\title{
Eccentric origins of creativity
}

\section{Did the genes underlying schizophrenia drive human evolution?}

\begin{tabular}{l|l} 
The Madness of Adam and Eve: \\
How Schizophrenia Shaped \\
Humanity \\
by David Horrobin \\
Bantam: $2001.275 p p . £ 18.99$ \\
Daniel Nettle
\end{tabular}

David Horrobin's preface promises us an intellectual Odyssey, and inasmuch as the range of the Odyssey was great, and its feats bold, his promise is fulfilled. This book contains more than just one bold argument - it has actually three connected but quite distinct major theses in one slim volume.

The first thesis starts from the undeniable truth that schizophrenia is an evolutionary puzzle. It is substantially genetic, moderately common in all human populations, and known to be associated with reduced reproductive success. How, then, do the genes underlying it persist at such frequency?

Horrobin's answer is that the traits that underlie schizophrenia are also found in many individuals who are not ill and who are among the most creative and successful members of society. Thus, the genes are maintained by positive selection on those who avoid frank illness, balanced by negative selection on those who do become ill.

Evidence for the co-occurrence of psychosis and creativity in families has been amassing for some time. Many links in the chain of causation still need to be filled in more solidly, though. For example, although theories involving the evolution of creativity rest on the notion that creative people enjoy increased reproductive success, this has never been demonstrated empirically for any modern or traditional society. In traditional societies, much of the variation in reproductive success can be explained simply by wealth, and neither artists, original though they are, nor schizotypal groups those with behavioural eccentricities similar to but less severe than seen in true schizophrenia - tend to be high achievers in narrow financial terms.

The book's second thesis is that the neurobiological basis of schizophrenia concerns the metabolism of fatty acids. This radical claim has hovered at the margin of psychiatric research for some years. Horrobin, its chief evangelist, argues eloquently that the time has come to give it a more central position. The model can in fact be reconciled with more conventional explanations involving the chemical transmitters between neural cells, or altered neuroanatomy, as fatty acids are involved in both neurotransmission and the growth of neural circuitry. Most significantly, the fatty-acid model
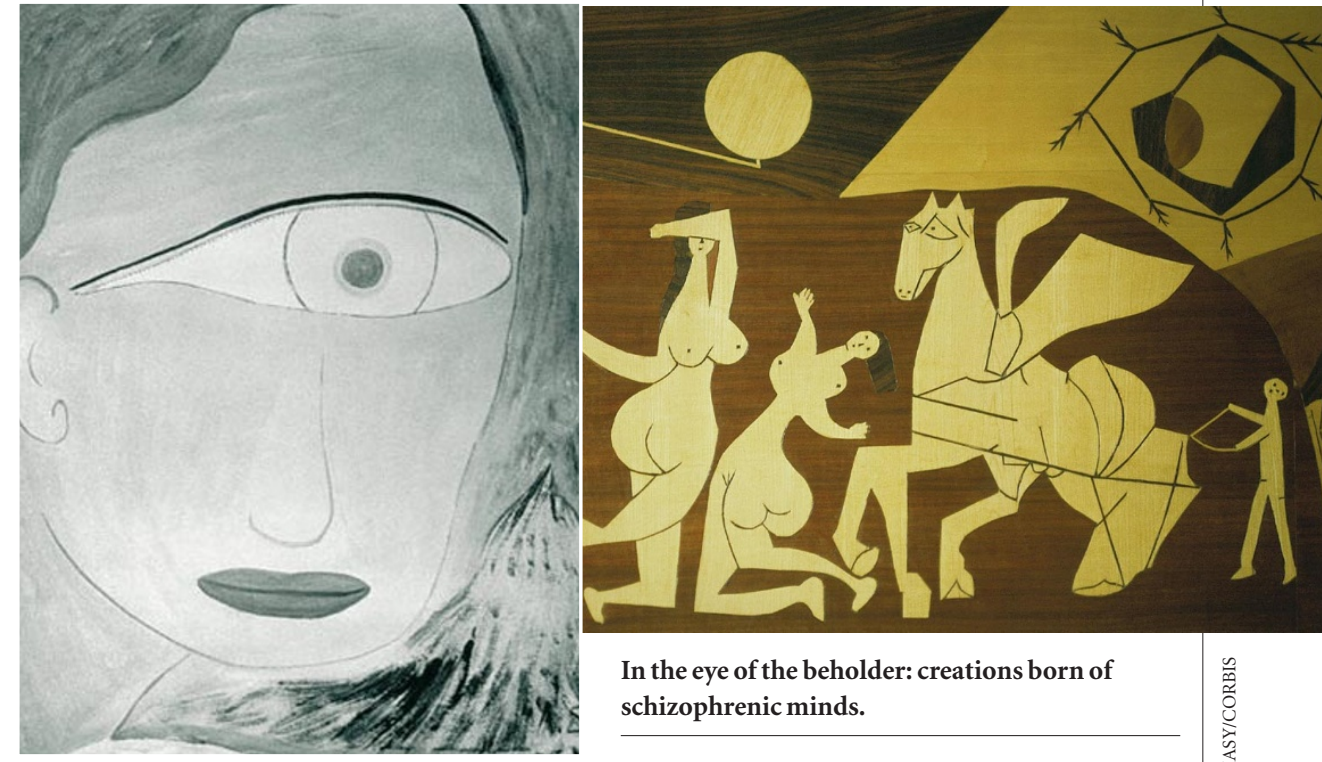

In the eye of the beholder: creations born of schizophrenic minds.

offers at least a possibility for developing new treatments in an area where medical progress has been stubbornly slow.

Horrobin's third thesis is more troublesome. He subscribes to the 'Big Bang' theory of human evolution, which tries to identify a key change at the origin of anatomically modern humans that gave rise to the full flowering of art, culture, language, technology and global conquest in a single step. Horrobin's version of the great leap forward is a change in fatty-acid production that radically enhanced neural connectivity within the brain. These very changes, Horrobin argues, are those associated with schizophrenia. He writes: "Without the genes which in combination cause schizophrenia we would be like Neanderthals or Homo erectus - large-brained, clever, but lacking that lust for change and creative spark that have so dramatically distinguished our species from our immediate predecessors".

This idea is problematic. Language, symbolism, culture and technological change are universal properties of all humans, whereas the genes that produce schizophrenia are restricted to a small minority of the population. Schizotypy cannot therefore be a central part of what distinguishes us from other hominids. Indeed, there is a deeper problem, for if schizotypal genes have an overwhelming selective advantage, as Horrobin supposes, then they should become universal in the population. But this has not happened. The real evolutionary question is why the genes relating to psychiatric disorder are neither vanishingly rare nor universal, but occur at a troublesome middling frequency, too common to be explained by genetic drift and too rare to be unequivocally adaptive.

Although he expounds his thesis elegantly, Horrobin is occasionally unclear about the logic of his evolutionary explanation. $\mathrm{He}$ dismisses previous accounts of human evolution, which promote social complexity or sexual selection as primary factors, in favour of his hypothesized change in phospholipid metabolism. However, the hypotheses he dismisses concern the ultimate causes of evolutionary change - selection pressures - whereas his model is one of proximate causation. An account of selection pressures is still required to explain why it is so good to be creative, and here we must fall back on such factors as sociality and sexual selection once again.

This is a popular work rather than a monograph, which has both advantages and disadvantages. On the positive side, the book is vivid, sweeping and readable, although sometimes paragraphs repeat themselves almost identically within a few pages of one another. On the negative side, the level of scientific attribution is very poor. There is an extensive bibliography, but it does not follow the structure of the book. As a result, it is impossible to trace the references to the studies alluded to in the text. Some results are not attributed at all, which is a shame, because the writing clearly comes from a good knowledge of the literature. Overall, the book is highly stimulating, but perhaps overreaches itself when it tries to turn an interesting and plausible argument about psychosis into an explanation of how we as a species evolved.

Daniel Nettle is at 10 Bears Hedge, Oxford OX4 4JJ, UK. 